\title{
BASES TEÓRICAS PARA O ENSINO DA ESCRITA
}

\author{
Manoel Luiz Gonçalves Corrêa* \\ Universidade de São Paulo \\ São Paulo, São Paulo, Brasil
}

\begin{abstract}
Resumo: Este trabalho estabelece parâmetros teóricos para a elaboração de conceitos de trabalho para o ensino da escrita (STREET, 2009), partindo da relação entre as perspectivas etnográfica e discursiva, mas fixando-se nesta última. Busca-se, em síntese, estabelecer parâmetros para a elaboração de conceitos de trabalho que não dissociem reflexão linguística (fundada no funcionamento da língua, do texto e do discurso) e reflexão sobre a escrita e seu ensino. A finalidade visada no ensino da escrita é fazer com que os conceitos de trabalho, aplicáveis em sala de aula, sejam permeáveis às diferentes situações da prática didática criadas pelos diferentes sujeitos nela envolvidos. A expectativa é que, assim elaborados, à medida que se fundamentem em parâmetros teóricos explícitos para o tratamento das questões de escrita, se distanciem da prática mais comum, que fixa modelos para reprodução.
\end{abstract}

Palavras-chave: Fundamentos Teóricos. Ensino. Escrita.

\section{INTRODUÇÃO}

Contrariamente ao senso comum, que afirma que "na prática, a teoria é outra", este trabalho se sustenta no fato de que não há prática sem teoria, procurando firmar a ideia de que a prática, com reflexão teórica, é outra. Meu objetivo é estabelecer bases teóricas para a elaboração de conceitos de trabalho (STREET, 2009, p. 1) para o ensino da escrita, partindo da relação entre as perspectivas etnográfica e discursiva, mas fixando-me nesta última. Partindo de Street (2009), entendo os conceitos de trabalho aplicados à produção escrita como instrumentos didáticos formulados a partir de qualquer das dimensões da linguagem com a finalidade de oferecer aos

\footnotetext{
* Professor Associado, Pesquisador CNPq, Livre-docente em Linguística Aplicada.
} 
alunos elementos para reflexão e intervenção na sua própria escrita. Eles visam a abrir possibilidades de os alunos se moverem no trânsito entre diferentes práticas escritas, facultando-lhes a entrada para aquelas que eles ainda desconhecem. Como ilustração, opor perfectividade (uso, por ex., do tempo verbal no pretérito perfeito) à imperfectividade (uso, por ex., do pretérito imperfeito), além de destacar um traço morfológico ligado à flexão verbal do português (atinente, portanto, à gramática da língua) pode servir também como recurso para marcar, no plano textual, dois planos narrativos ou dois diferentes pontos de vista sobre o que se narra. Tomar, portanto, as marcas de perfectividade e imperfectividade como conceitos de trabalho na produção escrita é conceber essa distinção como um instrumento didático para a produção do texto. No entanto, a formulação de conceitos de trabalho não se dá, direta e imediatamente, da língua para o texto, pois não se trata simplesmente de aproveitar uma distinção gramatical e aplicá-la no uso da língua. Sua efetividade depende, antes de tudo, de seu enquadramento numa concepção de escrita. Esse passo, que considero prévio ao estabelecimento de conceitos de trabalho, é o que procuro dar no presente trabalho. Em outras palavras, pensando especificamente na produção escrita, busco fixar, de uma perspectiva discursiva, fundamentos teóricos que não dissociem reflexão linguística (fundada no funcionamento da língua, do texto e do discurso) e reflexão sobre a escrita e seu ensino.

A novidade da proposta reside na tentativa de criar condições para que os conceitos de trabalho, aplicáveis em sala de aula, sejam permeáveis às diferentes situações da prática didática protagonizadas pelos diferentes sujeitos nela envolvidos. A expectativa é que, assim elaborados, ao mesmo tempo em que se fundamentem em parâmetros teóricos explícitos para o tratamento das questões de escrita, se distanciem da prática mais comum, que é a de fixar fórmulas para reprodução. No ensino da escrita por meio de gêneros do discurso, por exemplo, essa prática mais comum tende a propor para os gêneros um estatuto que não ultrapassa sua formulação puramente verbal, plena de didatismo, mas maximamente esvaziada de seu conteúdo sócio-histórico. Como tais, os modelos fixos acabam por se constituir, inapropriadamente, no ponto de chegada tomado como finalidade da prática didática. 
Contra essa prática, recorro a uma afirmação de Vygotsky: "estudar alguma coisa historicamente significa estudá-la no processo de mudança" (VYGOSTSKY, 1988, p. 74). O autor faz essa afirmação quando tematiza o problema do "conhecimento fossilizado". Segundo Vygotsky, a forma comportamental fossilizada é "o final de uma linha que une o presente ao passado” (VYGOTSKY, 1988, p. 74) e se apresenta como comportamento "automático e mecânico". Os modelos fixos que têm servido de diferentes maneiras a diferentes propostas de ensino da escrita também se apresentam como comportamentos linguísticos automáticos, mecânicos e fossilizados No entanto, o trabalho didático que parte de modelos fixos, quando contraposto ao estudo histórico das formas fossilizadas de comportamento, corre o risco de desconsiderar justamente a história que neles «se fossilizou». Dito de outro modo, a história de um gênero do discurso continua a ser registrada e a afetá-lo sempre que ele deixa seu estado "de correção", prerrogativa de seu caráter estático, para entrar na dinâmica errante de seus usos, na qual ganha certa deriva em função das contribuições dos escreventes - dinâmica impossível de se prever no estado descarnado de modelo fixo.

A esse respeito, no ensino da escrita a partir de gêneros do discurso, merece atenção o uso de exemplos modelares de gêneros, tomados de sua existência concreta na vida social para servirem como ambientação didática para a introdução de um novo gênero. Ainda que marcados por sua realização num tempo e num espaço, sua reprodução dessubstanciada é o que insiste em retornar como prática e como expectativa de chegada ao final do percurso didático. Por sua vez, o processo de constituição dos gêneros é reduzido a uma sequência didática previamente determinada, podendo deixar em segundo plano a atenção desejável ao processo de escrita do aluno e à sua relação com a linguagem ${ }^{1}$. E se não é assim como "currículo formal", na qualidade de objetivos e programas, é muito comum que o seja como "currículo real", na qualidade de conteúdo de ensino da prática didática diária.

\footnotetext{
${ }^{1}$ As remissões ao processo de escrita do aluno são empréstimos que faço a vários textos de Abaurre (1989, 1990), Abaurre, Fiad e Mayrink-Sabinson (1997) e Geraldi (1996). Devo também a esses autores, mas sem responsabilizá-los pela perspectiva discursiva que assumo, a atenção ao processo da escrita, que, em relação ao processo de desenvolvimento da escrita do aluno, corresponderia a como olhar para esse processo.
} 
Defendo, aqui, maior atenção ao caráter movente da escrita ${ }^{2}$ com ênfase, portanto, em seu aspecto processual. O caráter movente da escrita se contrapõe à fixidez do escrito no espaço dos variados suportes (papel, tela etc.). Contrapondo-se a essa fixidez gráfica, esse caráter movente permite que, pelas mãos do escrevente, diferentes práticas sociais ${ }^{3}$ se encontrem e se hibridem.

Os três primeiros pressupostos teóricos para o ensino da escrita aqui apresentados derivam da concepção da escrita como processo. Outros dois, que interpretam o processo de escrita da perspectiva discursiva e que estão direta ou indiretamente relacionados aos três primeiros, são apresentados a partir da seção 2.4. Expostos os cinco pressupostos, apresento algumas considerações finais.

\footnotetext{
${ }^{2}$ Com a expressão "caráter movente da escrita" faço um paralelo com o caráter movente da linguagem desenvolvido por Mattos (2006). Esse caráter da linguagem decorre do fato de que "linguagem e mundo não são nem absolutamente independentes, nem totalmente identificáveis" (MATTOS, 2006, p. 231) e, também, do fato de que a linguagem deve ser apta a expressar o dinamismo que caracteriza tanto o homem quanto a realidade em que ele está imerso. Ora, a enunciação pela escrita, sendo uma forma de linguagem, não é nem absolutamente independente nem totalmente identificável ao mundo (e ao falado). Sua atualização, por outro lado, está apta a expressar o dinamismo das relações humanas e da própria realidade, amalgamando segmentos sonoros em palavras, relacionando as palavras entre si e sinalizando a prosódia. Tudo isso, com as letras e com o auxílio de outros recursos gráficos, como o espaço em branco entre palavras, a distinção entre maiúsculas e minúsculas, os sinais de pontuação, o espaço em branco dos parágrafos, a diagramação etc., o que, em conjunto, permite que o enunciado escrito, na qualidade de significante, expresse o seu próprio contexto e, ao mesmo tempo, aponte, de modo redundante, para o contexto de realidade que se constrói no próprio escrito, modalizando e, ao mesmo tempo, abrindo percursos de sentido. Eis um modo de definir o caráter movente da escrita. Na sequência, dou outras determinações ao caráter dinâmico da escrita.

${ }^{3}$ Faço referência, sobretudo, às práticas sociais de expressão oral ou, simplesmente, práticas orais, como são genericamente chamadas. Ressalve-se, porém, que privilegiar a relação do escrito com o falado não é simplificar a questão, seja pela quantidade de práticas orais e escritas envolvidas, seja pelos tortuosos caminhos de apropriação dessas práticas pelo escrevente, seja, por fim, pela intervenção do processo de enunciação em que soluções ad hoc de escrita, atinentes à pertinência dos enunciados ao diálogo proposto, são fornecidas pelo escrevente, podendo equivaler tanto a reprodução quanto a novidade no tocante ao gênero produzido. Por último, o privilégio à relação escrito/falado apenas exemplifica um dado da heterogeneidade da escrita, talvez o mais importante, mas não pretendo, com ele, negar a presença de outras práticas sociais na escrita diferentes daquelas de expressão oral.
} 
2 DISCUSSÃO

\subsection{FUNDAMENTO DIALÓGICO PARA O ENSINO DA ESCRITA: O PROCESSO DE ESCRITA SE DESENCADEIA A PARTIR DA MANIFESTAÇÃO DO DIÁLOGO EM CADA GÊNERO DO DISCURSO}

As denominações "gênero textual" e "gênero do discurso" têm sido consideradas como sinônimas (cf. MARCUSCHI, 2003). Apesar de guardarem, de fato, alguma semelhança no tocante ao espírito que norteia a proposta de ensino esboçada pelos Parâmetros Curriculares Nacionais de Língua Portuguesa, a opção por "gênero textual" e a forma como essa noção tem sido levada à sala de aula, deixa, a meu ver, ainda a descoberto dois aspectos constitutivos do gênero: seu caráter dinâmico e sua heterogeneidade.

Como se sabe, não é a primeira vez que, ao se buscar produzir uma norma geral institucionalizável como conteúdo escolar (no caso, a partir de um conceito e da classificação dos gêneros), aspectos teóricos menos imediatamente apreensíveis acabam desconsiderados, o que pode transformar uma proposta louvável em práticas já questionadas há muito tempo. No caso da institucionalização do ensino de língua portuguesa por meio dos gêneros, a ênfase parece ter recaído, apenas, no que, neles, é estável - como se a sociedade pudesse existir sem história, isto é, como se a mesma sociedade que herda normas e fixa comportamentos não se definisse, com a mesma força, por sua constante transformação. $\mathrm{O}$ caráter estático do gênero, associado ao privilégio de seu aspecto organizacional, deixa, portanto, de lado o caráter processual que está na base de sua constituição e de cada uma de suas ocorrências. Aproximando-me das ideias de Bakhtin (1992), proponho que, ao lado da relação entre esfera de atividade humana na sociedade e gênero como realidade de língua em discurso, acrescente-se o caráter histórico do gênero do discurso, o que permite pensar a íntima relação entre sociedade, história e língua/linguagem. Para marcar seu caráter histórico, não limitado à construção composicional do gênero nem a uma concepção de sociedade restrita ao seu aspecto organizacional, prefiro a denominação "gênero do discurso" a "gênero textual". 
A dinamicidade dos gêneros do discurso está diretamente relacionada à ideia de relações intergenéricas. Um modo de observar como elas são trazidas para um dado gênero é investigar os reinvestimentos do diálogo na produção dos gêneros do discurso. Reconhecer e utilizar nos gêneros esses reinvestimentos é, portanto, pôr-se em contato com uma dentre inúmeras formas de atomização - que se dão em diferentes planos - da propriedade dialógica da linguagem.

Em função de seu papel axial na apropriação que o escrevente faz de diferentes práticas, o reinvestimento do diálogo (quem fala/escreve para quem) num dado gênero é o seu alicerce, mas não se confunde nem com algo genuíno a ser mantido, nem, tampouco, apenas com a novidade do diálogo concretamente efetivado.

Se seu caráter dialógico é a base de sustentação do gênero, suas vigas mestras se constituem, por um lado, pelo tempo/espaço em que é produzido e, por outro, pelas réplicas que produz. Estas últimas cobrem, mas também sempre deixam em alguma medida descobertas certas regiões do dizer, sejam elas atinentes à memória pretérita, ao acontecimento presente ou à memória de futuro (cf. sobre esta última: BAKHTIN, 1992; GERALDI, 1996), temporalidades axiais da relação com a alteridade.

Encaminhando a formulação do primeiro fundamento teórico para o ensino da escrita, pode-se dizer, inicialmente, que a escrita se produz segundo gêneros do discurso e que qualquer caracterização/classificação de um gênero deve passar pelo diálogo que, nele, se reinveste. Do mesmo modo, a produção de um gênero do discurso (oral ou escrito) começa a ser exitosa quando se pode reconhecer alguma pertinência (temática, composicional ou estilística) à relação dialogal pensada pelo escrevente para aquele gênero. Uma vez considerado o diálogo no gênero em produção, impõe-se, para a formulação dos argumentos, a atribuição de papéis e relações - mais, ou menos, hierárquicas - aos participantes.

A evocação do diálogo nos gêneros regula, desse modo, a construção da interlocução imaginada na escrita (incluindo o destinatário imaginado) e, uma vez recriados os papéis nele apenas indicados, abrem-se as comportas de sentido de regiões específicas do já-dito, que, ao se imporem, são reconhecidas pelo sujeito como restrições que autorizam/desautorizam 
possibilidades de recorte. Naturalmente, essas regiões do já-dito podem corresponder a práticas sociais de expressão escrita ou não. Portanto, o diálogo marcado nos gêneros do discurso pode ser reatualizado de diferentes formas no ato de produção, o que, uma vez mais, atesta a heterogeneidade que constitui todo gênero. A inventividade na produção de determinado gênero é, nesse sentido, a capacidade de, ao levar em conta a presença do diálogo no gênero, distanciar-se das práticas de reprodução de modelos fixos, ainda comuns em sala de aula. Distanciando-se da reprodução, o escrevente retoma o processo de emergência dos gêneros, em que as contribuições das relações intergenéricas contam para a dinâmica de mudança e para o surgimento de novos gêneros do discurso.

Determinado pela propriedade dialógica da linguagem, o diálogo é um dado primordial e constitui, portanto, um dos fundamentos teóricos para a produção e leitura dos gêneros do discurso. Sua consideração indicativa merece a atenção de professores e alunos, não como uma camisa de força necessária para a reprodução de uma fórmula, mas como ponto de partida para, consideradas as relações intergenéricas previstas ou imprevistas e as relações entre esferas de atividade humana que lhes correspondem, estarem no gênero e criarem dentro/a partir dele.

\subsection{FUNDAMENTO INDICIÁRIO DO MATERIAL LINGUÍSTICO NA ESCRITA: O PROCESSO DE ESCRITA SE MARCA NAS PISTAS DEIXADAS NO FIO DO DISCURSO, MAS SUA EXPLICAÇÃO NÃO SE LIMITA AO ESTRITAMENTE LINGUÍSTICO}

Para produzir, a partir da presença do diálogo, a pertinência dos enunciados a um determinado gênero do discurso, dois caminhos se apresentam nas soluções ad hoc de escrita: por escolha e por exclusão. $\mathrm{Ou}$ seja, a possibilidade de participação de grande variedade de práticas orais na escrita (assim como de práticas sociais de expressão diversa da oral) se resolve segundo dois modos de o escrevente se representar como sujeito na escrita: a) como centro decisório que faz escolhas, crendo na transparência dos sentidos; e b) como estrategista que, ainda crendo em alguma transparência dos sentidos, busca se esquivar da imponderabilidade das 
respostas que seu dizer pode suscitar, procurando, nunca com total sucesso, balizar a zona de opacidade constituída pelo destinatário imaginado e pelas vozes representadas (e às quais replica) do já-dito.

Esses modos de o sujeito se representar dão indicações de que o processo de produção de sentido por meio da escrita não é transparente. Não há, em primeiro lugar, um diálogo com papéis inteiramente previstos para os interlocutores de um dado gênero. Trata-se, na maioria das vezes, de tipos mais ou menos previstos de relação (mais, ou menos, assimétricas) entre os participantes, o que não se confunde com estereotipia. Portanto, o diálogo aparece, sobretudo, como indicação do caráter dialógico de qualquer gênero. Além disso, o sentido de um enunciado (falado ou escrito) só ganha acabamento na réplica que provoca (BAKHTIN, 1992, p. 289326). Há, pois, uma parte imponderável do sentido não passível de soluções inteiramente conscientes, sendo o sujeito constrangido a contornar interdições por procedimentos de exclusão (cf., a propósito, FOUCAULT, 1996). Desse modo, não controlar integralmente o sentido é inscrever o processo de escrita, ao mesmo tempo, na história do já-dito e na luta por um dado sentido. Eis, portanto, naquilo que o constrange, as condições de aparecimento do estrategista.

Nessas soluções de escrita por procedimentos de exclusão, o sujeito procura se esquivar tanto da alteridade representada no diálogo efetivado quanto da alteridade representada pelas vozes do já-dito, buscando, com isso, preservar a figura solitária que ele representa para si no ato de escrever. No entanto, como o monólogo impõe a divisão do sujeito - e o faz talvez mais claramente em determinados estágios de domínio da escrita em função da produção simultânea de um falante e um ouvinte num único e mesmo escrevente -, falta sempre, nessa solidão loquaz da escrita, a parte do dizer situada numa zona mais opaca do sentido. Trata-se da zona de silêncio constituída pelo intervalo entre, por um lado, a figura que se representa como fonte do dizer pela escrita e, por outro, as figuras que são imaginadas como os interlocutores do diálogo em um determinado gênero às vezes multiplicados polifonicamente, às vezes reduzidos ao destinatário imaginado ou, em certos casos, ao próprio escrevente, que pode, além de se representar como fonte da escrita, acumular o papel de uma dessas figuras. 
Portanto, muito antes do ato de leitura que particulariza uma avaliação sobre o dito (o que se diz) e o dizer (quem e para quem se diz), a antecipação desse encontro impõe uma série de restrições ao escrevente na qualidade de leitor de seu próprio texto, situando-o num dado processo histórico de produção do sentido. Isso explica os procedimentos de edição mobilizados por ele, tais como, rasuras, alterações da ordem ou mudança de palavras na oração, uso do recurso de apagar etc. Esses e muitos outros procedimentos que se observam na superfície do texto e marcam a execução do processo de escrever dão pistas do processo histórico em que o sujeito se insere ao reconstruir o diálogo quando produz/lê um gênero. Ao mesmo tempo, são pistas seguras de que, no ensino da escrita, não basta lidar apenas com essas supressões, acréscimos, substituições, deslocamentos, mas, também, com o processo histórico de construção do sentido, a que esses procedimentos respondem. Não basta, tampouco, procurar reproduzir um suposto diálogo fixado previamente para o gênero.

$\mathrm{O}$ aspecto processual da escrita consiste no desenrolar de um trabalho que começa no encontro intersubjetivo, produtor de qualquer fato de linguagem, e que, ao menos indiciariamente ${ }^{4}$, se marca no fio do discurso. A localização de um indício não corresponde, porém, a encontrar uma explicitação formal no texto, de tal modo que representasse, de forma acabada e clara, o alcance de determinado procedimento, por exemplo, o de edição. Lidar com indícios é submeter a localização empírica de uma marca à sua relação com o discurso e, portanto, com implicações linguísticas, sociais e históricas; é reconhecer que essa relação não corresponde a uma representação fiel do fato, mas que tem, com ele, uma relação problemática (a propósito da relação problemática com o fato em si, conferir, no campo da história: GINZBURG, 2009).

Conceber o sentido como dinâmico e o sujeito como figura produzida no discurso são, talvez, as duas consequências principais da consideração do aspecto movente da escrita. É importante reter, portanto, que o diálogo na produção e na leitura de todo gênero é já - bem ou mal -

\footnotetext{
${ }^{4}$ A consideração de indícios como formas de marcação do processo da escrita é assunto tratado por vários autores (TFOUNI, 1992; ABAURRE; FIAD; MAYRINK-SABINSON; GERALDI, 1995).
} 
antecipado na divisão do sujeito e indiciado no ato de escrever. Em suma, um segundo fundamento teórico para o ensino da escrita é o de considerá-la como processo indiciado no fio do discurso, mas só explicável no movimento da história.

\subsection{FUNDAMENTO PRAGMÁTICO-ENUNCIATIVO DE TODA PRODUÇÃO ESCRITA: O PROCESSO DE ESCRITA SÓ SE DEIXA OBSERVAR QUANDO A ESCRITA SE REALIZA COMO UM MODO DE ENUNCIAÇÃO}

A presença do diálogo no gênero do discurso e o modo de explicar as pistas do processo de escrita deixadas no fio do discurso não poderiam ser enunciados como dois fundamentos para o ensino da escrita sem que considerássemos a escrita como um modo de enunciação e não apenas como um código.

A faceta processual da escrita se evidencia quando ela é considerada como modo de enunciação, ou seja, como um dos modos de atualização da língua, ou, ainda, como uma das maneiras de realização discursiva por meio das quais sujeito e sentido ganham forma. Assim entendida, não há relação dicotômica possível entre escrita e fala, pois sentido e sujeito se concebem, se conformam e se expressam por meio da mobilização de variadas práticas (orais, escritas etc.), mesmo quando apenas um único modo de enunciação (escrito ou falado) é utilizado. Seu aspecto processual marca, portanto, uma visão que se distingue da escrita considerada apenas em seu aspecto estático de código alfabético, referido, em geral, como modalidade escrita.

Como código - ainda que imperfeito do ponto de vista da representação do falado -, a modalidade escrita é um sofisticado recurso para representar o aspecto segmental da língua, tendo agregado, no decorrer da história, os sinais de pontuação, indicativos da relação sintaxe/prosódia/semântica. Limitado a esse papel de representação, no entanto, o código escrito serviria basicamente à transposição de sons em letras, o que autorizaria uma oposição radical entre fala e escrita. Por seu turno, a constituição heterogênea da escrita em relação à fala, por mim defendida de uma perspectiva discursiva (CORRÊA, 2004), se evidencia 
quando a escrita extrapola a sua função de código para constituir-se num dos modos de enunciação em que se produzem sujeito e sentido.

Ora, como ficou dito, sujeito e sentido são categorias para cuja emergência contam processos sociais e históricos. No que se refere ao sujeito, o indivíduo empírico que incansavelmente buscamos (em nós mesmos, nos outros, nos intercâmbios verbais) chega ao discurso por meio de um processo histórico que nos dá - sempre - uma versão de sua realidade empírica, isto é, temos acesso a ele como um produto históricodiscursivo, e não como indivíduo empírico. No que se refere aos sentidos, além da legitimação resultante de valoração histórica de certos sentidos em detrimento de outros, eles são afetados também pelo regime processual de tomada da palavra, ato que, situado entre lembrança e esquecimento, simula, a cada vez, reinaugurar o exercício da linguagem, renovando ou reafirmando sentidos.

As categorias de sentido e de sujeito são, portanto, da natureza do acontecimento discursivo ${ }^{5}$, que, por sua vez, na fala ou na escrita, é historicamente produzido, não podendo ser reduzido apenas a um evento situado num tempo - redução a um evento datado - e num espaço redução a um evento sociogeograficamente circunscrito. Não se restringindo ao dado cronológico e sociogeográfico do encontro, o acontecimento discursivo não pode ser entendido como lugar em que a transparência dos sentidos e a centralidade do sujeito se produzem, nem, tampouco, como um encontro fantasmático que simplesmente ratificaria

\footnotetext{
${ }^{5}$ Para Pêcheux, em texto originalmente publicado em 1988, o reconhecimento de que há um jogo entre estrutura e acontecimento na discursividade não obriga que se tenha, como subproduto, que todo discurso seja "independente das redes de memória e dos trajetos sociais nos quais ele irrompe. Em vez disso, trata-se, segundo o autor, de sublinhar que, só por sua existência, todo discurso marca a possibilidade de uma desestruturaçãoreestruturação dessas redes e trajetos: todo discurso é o índice potencial de uma agitação nas filiações sócio-históricas de identificação, na medida em que constitui ao mesmo tempo um efeito dessas filiações e um trabalho (mais ou menos consciente, deliberado, construído ou não, mas de todo modo atravessado pelas determinações inconscientes) de deslocamento no seu espaço: não há identificação plenamente bem sucedida, isto é, ligação sócio-histórica que não seja afetada, de uma maneira ou de outra, por uma 'infelicidade' no sentido performativo do termo - isto é, no caso, por um 'erro de pessoa', isto é, sobre o 'outro', objeto de identificação” (PÊCHEUX, 1990, p. 56-57).
} 
sentidos fixados alhures para reprodução infinita e formas-sujeito ${ }^{6}$ instaladas exclusivamente para o assujeitamento. A escrita tomada como modo de enunciação é, portanto, também, um lugar em que se produzem sujeito e sentido como categorias históricas (no sentido dado na Nota 1, cf. aqui mesmo).

No processo social envolvido na tomada da palavra - sendo, naturalmente, a tomada da palavra por meio da escrita apenas uma de suas formas -, atua sempre alguma hierarquização dos participantes, resultando, em não poucos casos, na interdição de certos intercâmbios verbais. Ao contrário do que o senso comum sociológico disseminado nas ciências da linguagem pode fazer pensar, essa hierarquização não obedece apenas a modelos organizacionais de distribuição social da tomada da palavra segundo papéis sociais bem definidos, mas uma vez mais é, sobretudo, produto de valorações de caráter histórico, as quais afetam papéis sociais, distribuição social da palavra e, finalmente, o modo como sentido e sujeito são produzidos no discurso.

Considerando-se, ainda, o aspecto histórico, os próprios modos de enunciação falado e escrito gozam de diferentes valorações na sociedade de acordo com o momento histórico. No tipo de organização social em que vivemos, considerados os papéis do modo de enunciação escrito: a) na

\footnotetext{
${ }^{6}$ A noção de forma-sujeito em Pêcheux marca, por um lado, seu distanciamento da ideia de centralidade do sujeito do discurso. Exemplifica isso o comentário, feito de passagem em livro originalmente publicado em 1975, sobre a noção de "atividade" em Piaget. Segundo o autor: "a atividade não é a mesma coisa que a 'prática'; a prática não pode ser a prática de um sujeito: não há, para sermos exatos, prática de um sujeito; há apenas os sujeitos de diferentes práticas" (1997, p. 218). Nota-se, pois, nessa recusa da noção de atividade, a afirmação da não centralidade do sujeito, formulação que mantém o assujeitamento como um dos elementos da forma-sujeito. Por outro lado, em outro momento, pode-se ler, em relação ao sentido, um modo não assujeitado de assunção da forma-sujeito: "todo enunciado é intrinsecamente suscetível de tornar-se outro, diferente de si mesmo, se deslocar discursivamente de seu sentido para derivar para outro (a não ser que a proibição da interpretação própria ao logicamente estável se exerça sobre ele explicitamente). Todo enunciado, toda sequência de enunciados é, pois, linguisticamente descritível como uma série (léxico-sintaticamente determinada) de pontos de deriva possíveis, oferecendo lugar a interpretação. É nesse espaço que pretende trabalhar a análise de discurso" (1990, p. 53, originalmente publicado em 1988).
} 
planificação administrativa da sociedade; b) na uniformização e na distribuição dos instrumentos documentais por meio dos quais os indivíduos se beneficiam dessa planificação, ganhando uma identidade jurídica; e c) na homogeneização a que, na qualidade de sujeitos jurídicos, os indivíduos estão adstritos - para que, ganhando identidade jurídica, possam se beneficiar da igualdade formal de direitos e deveres garantida a todos; considerados, portanto, esses papéis de planificação, de uniformização e de homogeneização desempenhados pela escrita, não é difícil constatar o alto valor social que, até hoje, lhe é atribuído.

Em síntese, reconhecer o caráter processual da escrita é reconhecê-la como modo de enunciação submetido à heterogeneidade dos usos e não apenas como codificação gráfica dos segmentos sonoros, isto é, como código alfabético, preso - mas exclusivamente no momento de dotar uma língua de escrita - a uma variedade normalizada para ser codificada, embora, nem assim, homogênea.

Esse não é apenas mais um dos fundamentos para o ensino da escrita, pois está na base dos dois primeiros fundamentos enunciados. Escolhi mencioná-lo neste ponto porque sua consideração pode iluminar também a relação entre as perspectivas etnográfica e discursiva, que discutirei no item seguinte. Acredito que conceber a escrita como modo de enunciação pode dar, do ponto de vista linguístico-discursivo, uma dimensão para o seu ensino em que sujeito e sentido sejam pontos para reflexão e, do ponto de vista etnográfico, pode permitir o reencontro com o indivíduo empírico, ainda que como dado problemático de realidade a ser considerado, o que discutirei na sequência.

\subsection{FUNDAMENTO DISCURSIVO DO MATERIAL LINGUÍSTICO E DO SUJEITO NA ELABORAÇÃO DE CONCEITOS DE TRABALHO}

Um esclarecimento prévio se impõe: a perspectiva discursiva que menciono é aquela constituída pela análise dialógica do discurso (de cunho bakhtiniano) e pela análise do discurso francesa, as quais vêm aqui associadas em função do fato de que ambas consideram a dimensão sóciohistórica na produção do sentido e do sujeito do discurso. 
Conceitos de trabalho captam melhor o processo de escrita quando, em lugar de se limitarem ao aspecto verbal, incluem simultaneamente: a) o presumido social dos gêneros do discurso (concebido como a amplitude sociocultural e histórica do próprio aspecto verbal dos gêneros); e b) a relação problemática entre sujeito empírico e sujeito do discurso.

Retomo o objetivo inicial deste trabalho: estabelecer parâmetros para a elaboração de conceitos de trabalho que não dissociem reflexão linguística e reflexão sobre a escrita e seu ensino.

\subsection{1 "Aspectos ocultos do letramento" vs. "presumido social"}

Na exposição do segundo fundamento teórico, ficou dito que não basta detectar o que falta ou o que sobra no fio do discurso, pois há mais que considerar além do aspecto estritamente linguístico. Neste ponto, partindo da livre exploração de conceitos nascidos em teorias diferentes, discuto por que, do lado da etnografia, a noção de "aspectos ocultos do letramento" (STREET, 2009) não pode corresponder, do lado da perspectiva discursiva, ao de "presumido social" (VOLOSHINOV/BAKHTIN, 1926-s.d.). Além de lançar alguma luz no diálogo entre a perspectiva etnográfica e a discursiva, ressalto que, no ensino da escrita, a atenção não pode concentrar-se apenas no aspecto verbal do gênero do discurso. Menos ainda, a elaboração de conceitos de trabalho com finalidade didática.

Parto, pois, da tentativa de aprofundar a reflexão sobre o que falta ou o que sobra no fio do discurso ( $2^{\circ}$ fundamento teórico aqui exposto), utilizando, para tanto, as oposições entre "verbal" + "extraverbal" (e seu correlato: "presumido social"), por um lado, e "aspectos ocultos do letramento", por outro.

Procurando abordar duas questões que me parecem preocupantes e dialogar com a reflexão de um dos autores que mais têm contribuído para investigar a relação escrita/fala sob uma base não dicotômica, discuto a noção de "aspecto oculto do letramento" (STREET, 2009) e a de sujeito empírico, noção que pode ser um divisor de águas na relação entre as duas perspectivas em questão. Destaco, portanto, dois aspectos cuja investigação 
me parece importante e inadiável: a) o de qual relação pode haver entre aspectos ocultos do letramento (STREET, 2009) e presumido social (VOLOSHINOV/BAKHTIN, 1926-s.d.); e b) o da relação problemática entre sujeito empírico e sujeito da linguagem.

No que se refere à relação entre aspectos ocultos do letramento e presumido social, penso que vale a pena começar pela noção de enunciado concreto, desenvolvida no chamado Círculo de Bakhtin. Como se sabe, na formulação dada por Voloshinov/Bakhtin(1926/s.d.), o enunciado concreto é constituído por uma parte verbal e por uma parte extraverbal. Minha preocupação aqui é aplicar essa distinção para o gênero do discurso, que é, como se sabe, constituído de enunciados genéricos (concretos).

Por seu turno, a menção a letramento oculto é antiga nos trabalhos de Street. Em seu livro de 1984, ele já fala a respeito (cf. a síntese que fiz sobre esse tema em CORRÊA, 2011).

Em trabalho de 2009, Street refere-se aos aspectos ocultos do letramento acadêmico presentes na relação de ensino e aprendizagem e os exemplifica por meio de dados verbais que ficam ocultos nessa relação e de cuja falta se ressentiriam o aprendiz da escrita acadêmica e o próprio texto por ele produzido em função dos aspectos que omite. Nesse sentido, a expressão "aspectos ocultos do letramento" refere-se claramente à materialidade verbal não explicitada. A dúvida quanto a isso é saber em que medida é possível dizer tudo a respeito de um gênero. A completa explicitação de sua constituição formal seria suficiente para evitar a presença de aspectos ocultos do letramento no ato da produção dos textos?

Embora a elaboração de conceitos de trabalho seja uma saída interessante para o ensino da escrita, o tratamento dos aspectos ocultos do letramento corre o risco de mantê-los restritos a algumas características da estrutura composicional ou às escolhas léxico-gramaticais que caracterizam os estilos de gênero. Como uma alternativa a essa posição, tenho defendido que há aspectos ocultos do letramento que não são enunciáveis na estrutura composicional (Cf. CORRÊA, 2011). Trata-se daquilo que, nos gêneros, pertence ao campo do extraverbal, isto é, que se vincula a "presumidos sociais". Estes ultrapassam uma interpretação pragmática restrita para alcançarem uma dimensão sócio-histórica que escapa à transparência do 
estritamente linguístico. A meu ver, os presumidos sociais, que afetam tanto a produção quanto a leitura do texto, são equivocadamente vistos:

a) ora como algo ausente porque pressuposto - visão que se equivoca ao denominar como ausente algo que está no aspecto verbal, ainda que pressuposto, e, portanto, presente nele;

b) ora como algo ausente porque implícito - visão que se equivoca ao denominar como ausente algo que está implicitado no contexto situacional de que o verbal não se separa e, portanto, também nele presente;

c) ora como uma falta no aspecto verbal - falta sentida, por exemplo, pela perspectiva etnográfica que, por vezes, privilegia uma visão do verbal como o lugar da transparência do sentido.

Parece claro que os presumidos sociais nunca podem ser transparentes, já que são... presumidos e, como tais, dão opacidade ao que se poderia querer como transparência. Do mesmo modo, nunca podem ser apenas pressupostos ou implícitos já que isto seria produzi-los como verbais e não como extraverbais. Por sua vez, a falta de algum elemento de natureza verbal pode indicar não propriamente uma falta, mas um lugar que marca uma presença: o de alguma relação intergenérica relevante para o escrevente, mas ainda não reconhecida para o gênero produzido.

Para abreviar uma discussão que precisaria ser mais longa, os gêneros do discurso, tal como frequentemente ensinados na escola, têm sido vistos, preferencialmente, por um viés tipológico. Tende-se a ensinar, num retorno ao ensino por meio de modelos de textos, uma série de gêneros do discurso, orais ou escritos, que, embora não seja considerada pela teoria como uma lista exaustiva, privilegia a tipologização e, por essa via, chega à sala de aula sob a forma de uma sucessão de modelos repassada ao aluno.

Observe-se que essa prática didática se distancia bastante daquela que envolve o trabalho com o reinvestimento do diálogo em cada gênero, discutido no $1^{\mathrm{o}}$ fundamento teórico aqui exposto. Por um lado, o reinvestimento do diálogo dá indicações (mas apenas indicações) sobre os atores que se defrontam habitualmente em cada gênero. Por outro lado, ele repõe o caráter dialógico fundante da linguagem, abrindo espaço para alguma singularidade na apreensão de um determinado gênero, o que favorece apropriações inéditas ao permitir que o escrevente busque, na palavra, a força do argumento e não a estrutura repetível do modelo. 
Para saber onde o escrevente deve buscar essa palavra (já que ele não terá o modelo fixo para seguir), basta não reduzir, indevidamente, sua capacidade de linguagem ao domínio de um único gênero falado (a conversa cotidiana), tampouco ao domínio parcial de uma única competência (a de falar). Tal redução corresponde a negar ao escrevente qualquer possibilidade de transformar em argumento os saberes que, de maneira formal ou informal, direta ou indireta, lhe chegam das diferentes práticas sociais de que participa. Negar essa circulação de saberes na escrita anula o efeito das relações intergenéricas nas atualizações particulares que um dado gênero pode ter, restando como saída privilegiar sua estabilidade em detrimento de sua dinâmica, o que, também indevidamente, desvincula a produção atual do gênero da característica fundante de sua própria gênese. Estando, pois, aberto à simulação de variadas relações entre sujeitos, a presença do diálogo no gênero não se reduz a um ponto de partida prefixado, já que ele não se resolve nunca por reprodução de modelo, mas por experimentação de diálogos possíveis.

É sabido, porém, que o ensino por meio de gêneros do discurso parece ter redescoberto a normatividade, desta vez a partir de modelos de gêneros. É evidente que há normas mais ou menos fixadas para a produção dos gêneros, mas é importante não se esquecer de outras regularidades que atuam sobre a estabilidade do gênero, isto é, no sentido de sua dinamicidade, atuando, portanto, para a sua transformação. Um dos caminhos para buscá-las é, a meu ver, o das relações intergenéricas, fenômeno que, todavia, tem sido pouco explorado como móvel da produção do gênero. Em contrapartida, tem tido mais atenção o estabelecimento de hierarquias entre gêneros - o que ilustra a preocupação classificatória dominante. Não se sustenta, do ponto de vista linguístico, a classificação dos gêneros em simples e complexos ${ }^{7}$. Não me parece, pois, valoração hierárquica o que proporia, de fato, Bakhtin na conhecida passagem em que

\footnotetext{
${ }^{7}$ Cintra faz uma importante relativização a propósito da evolução filogenética dos gêneros (de primários a secundários). Para a autora, numa abordagem ontogenética dos gêneros, “os fatos não se dão num recorte tão preciso, mesmo porque as crianças estão continuamente em contato com a sociedade adulta e com sua prática cotidiana dos gêneros secundários" (CINTRA, 2009, p. 39).
} 
distingue "gêneros primários" e "gêneros secundários". Pelo contrário, prefiro ler, nessa distinção, a proposição do diálogo cotidiano ou, simplesmente, do diálogo, como motor das relações dialógicas que caracterizam a linguagem de modo geral (cf., a propósito, MARCHEZAN, 2008).

Além de ser um ganho em relação à visão dicotômica entre fala e escrita, as relações intergenéricas marcam, nos consensos ou nos dissensos provocados por esses cruzamentos entre gêneros, não só o que verbalmente fica dito, mas também o que certos encontros de gêneros (e não outros) eis um novo modo de marcar uma entoação própria para o enunciado concreto - podem trazer de extraverbal. Em outras palavras, também no estabelecimento das relações intergenéricas atuam presumidos sociais. Se eles não têm merecido a devida atenção, talvez seja porque nunca estão transparentemente verbalizados nos gêneros do discurso. Ora, essa desatenção às relações intergenéricas leva ao risco de se produzir uma mecanicização no ensino dos gêneros do discurso, com atenção exclusiva à parte verbal do gênero do discurso e desprezo de sua parte extraverbal.

\subsubsection{Sujeito empírico vs. sujeito do discurso}

A segunda questão que deve ser levada em conta na associação entre a perspectiva etnográfica e a discursiva é a da relação entre sujeito empírico e sujeito de discurso.

Se, por um lado, há um sujeito empírico ao qual não se pode negar uma realidade, por outro lado, seu aparecimento na linguagem nunca se dá de forma direta. $\mathrm{O}$ "fato em si", da existência do sujeito empírico obedece à sempre problemática questão da referência. Mesmo numa perspectiva que só leve em conta a interação entre os sujeitos já não se pode conceber um sujeito plasmado na linguagem tal como em sua própria existência empírica. A referência (ao mundo, ao outro e a si mesmo) só acontece no processo de enunciação. Não se trata, pois, de uma relação linguagem/mundo (sem mediação), em que as coisas, as pessoas e o próprio sujeito apareceriam como tais na sua representação pela linguagem.

\footnotetext{
${ }^{8}$ Procurando transpor a ideia nela contida, tomo a expressão de Ginzburg (2009).
} 
$\mathrm{Na}$ constituição do sujeito da linguagem estabelece-se uma relação problemática com o mundo, com as coisas e com o próprio sujeito empírico em função da interveniência da relação de alteridade. O sujeito passa, pois, a ser redefinido pela relação de alteridade constitutiva de toda enunciação. Se, isoladamente, o sujeito empírico é um "fato em si", um dado de realidade, não é como tal que ele articula a palavra e enuncia, já que está irremediavelmente marcado pela alteridade junto com a qual se constitui.

Trata-se, portanto, do sujeito da enunciação (BENVENISTE, 1976), do sujeito representado no enunciado como locutor (DUCROT, 1972), do sujeito representado no texto como organizador textual (ADAM, 2008), do sujeito escritor representado no texto literário como autor-criador (BAKHTIN, 1992); do sujeito do discurso (PÊCHEUX, 1997). Se se tiver presente essa ideia, já não se poderiam tratar os sujeitos apenas de um ponto de vista etnográfico ou, no mínimo, seria preciso definir uma etnografia discursiva.

Encaminhando as conclusões deste fundamento teórico para o ensino da escrita, retomo, numa breve síntese do que foi dito, a discussão sobre a parte extraverbal do enunciado concreto.

No enunciado concreto ou no gênero do discurso é preciso lembrar que sua parte extraverbal fica indiciada, mas nunca diretamente representada: a) nem nas construções de tempo/espaço (que ultrapassam o tempo cronológico e o espaço físico); b) nem nos recortes do já-dito (propostos com base na representação que o escrevente faz da presença do diálogo no gênero e não em uma suposta reprodução estrita de um diálogo modelar); c) nem, tampouco, na relação problemática entre sujeito empírico e sujeito do discurso, que acabo de expor. Todos esses recursos, centrais na produção dos gêneros do discurso e perfeitamente compreensíveis quando se toma contato com um determinado gênero do discurso, lançam mão de recursos extraverbais que ultrapassam os não-ditos de natureza verbal, tais como os não-ditos dos pressupostos, dos implícitos e daquilo que faltaria para caracterizar formalmente um dado gênero.

Ora, na qualidade de indicadores de apostas extraverbais, esses recursos se combinam para servir tanto ao trabalho do escrevente como centro do dizer (quando, assim se representando, desliza, incauto, pela 
ilusão de transparência do sentido), quanto ao seu trabalho como estrategista (quando, ainda sob a ilusão de transparência do sentido, busca contornar regiões de sentido em que a opacidade da linguagem se impõe). Como a mobilização do extraverbal tem o caráter de uma aposta - que projeta, perigosamente, o pacto do interlocutor com o sentido produzido e com a sua opacidade -, só as réplicas ao conjunto "expressão verbal + extraverbal" podem consumar o extraverbal como presumido social ou não. Dito de outro modo, o "extraverbal" envolve a consideração de um aspecto social mais amplo (VOLOSHINOV/BAKHTIN,1926-s.d.), isto é, também a sua compreensão pode ser vista como "prenhe de resposta" (BAKHTIN, 1992, p. 291). Na escrita, ele não ganha acabamento com o último ponto final proposto pelo escrevente, já que sua mobilização não se resolve num preenchimento pragmático estrito por parte do escrevente, nem o extraverbal pode sempre ser visto como um dado cultural estável que o escrevente teria a prerrogativa de mobilizar sem sustos. Mobilizá-lo é mobilizar o pacto, sempre incerto, com o outro; é propor repactuação a cada vez.

Para concluir, o quarto fundamento teórico para o ensino da escrita pode ser enunciado da seguinte maneira: a atenção exclusiva ao aspecto verbal do gênero do discurso, em particular à sua construção composicional, desconsidera a parte extraverbal do gênero do discurso e, portanto, o "presumido social" que o acompanha e que atua tanto no conteúdo temático, quanto na construção composicional, quanto no estilo. Com efeito, os enunciados concretos apresentam tanto uma parte verbal quanto uma parte extraverbal, e não podem ser considerados apenas em função de sua parte verbal. Mais grave do que isso: por serem enunciados genéricos (pertencentes a gêneros do discurso), não podem ser interpretados sem a remissão ao gênero a que pertencem. Sendo, pois, intrinsecamente ligados a gêneros e não podendo ser vistos apenas em seu aspecto verbal, essa condição de existência do enunciado concreto é, também, uma condição para a existência do gênero. Não é, portanto, recomendável que se proponham conceitos de trabalho que tenham como alvo apenas o aspecto verbal do gênero do discurso. 
Uma consequência derivada desse fundamento teórico é o cuidado para não embaralhar as perspectivas etnográficas sobre o ensino da escrita e as perspectivas discursivas. Nestas últimas, a atenção à parte extraverbal do gênero pode marcar uma diferença importante em relação às perspectivas etnográficas, por vezes mais afeitas ao trabalho com a parte verbal dos gêneros do discurso. Em ambas, portanto, há a mesma busca de dar conta da amplitude das práticas verbais (a da escrita, no caso em questão) em função de seu papel na sociedade e na história, mas cada uma delas com abordagens para as quais é preciso demarcar as diferenças.

\subsection{FUNDAMENTO DISCURSIVO DA IDENTIDADE DO SUJEITO, CONSIDERADA A RELAÇÃO DE ALTERIDADE EM SEU SENTIDO FORTE: ALTERIDADE, HETEROGENEIDADE CONSTITUTIVA DA ESCRITA E REPRESENTAÇÃO}

As várias teorias linguísticas que consideram o caráter interacional da linguagem se diferenciam principalmente quanto à assunção do sentido fraco ou forte de alteridade e, para que esta discussão não seja confundida com a defesa cega de uma única posição, deixo desde logo estabelecido que ao menos as práticas didáticas têm muito a ganhar com a exploração dos dois sentidos de alteridade.

O sentido fraco de alteridade é, em geral, assumido quando perspectivas de cunho pragmático-enunciativo, ao tomarem o texto como categoria mais alta de interesse, identificam discurso com a noção difusa de uso da língua e língua com a ideia de estrutura ou de aparato funcionalestrutural. Por seu turno, o sentido forte de alteridade, assumido, em geral, pelas perspectivas discursivas, toma como categoria-limite o discurso, concebendo o texto, para dizer de forma breve, como uma conformação linguística resultante de determinações discursivas, e a língua, como um estado de cristalização de sentidos historicamente produzidos no discurso. Neste último caso, a língua seria uma espécie de memória que inclui desde o regime não marcado (menos marcado?) da literalidade (cf. POSSENTI, 1999) até a formação discursiva mais claramente marcada e identificável com um determinado regime de ordenação do dizer, podendo ele, inclusive, 
ser datado; mas ambos os regimes se constituindo, igualmente, por determinações sócio-históricas fossilizadas, embora transitórias e sujeitas a mudanças.

\subsubsection{Os sentidos fraco e forte de alteridade}

O sentido fraco de alteridade caracteriza-se pelo olhar que multiplica as diferenças e faz uma lista delas, permitindo-se, por esse procedimento de separação, distinguir, de uma só vez, o mesmo do diferente e os diferentes entre si. No ponto de partida, no entanto, situa-se uma concepção do outro, definida unicamente em função de uma identidade construída segundo o modelo $\mathrm{A}=\mathrm{A}^{9}$. Desse modo, a partir de si mesmo, imaginando-se como uma identidade isenta do outro, o sujeito poderia demarcar espaços para os outros, que estariam sempre fora de sua constituição como sujeito.

Esse procedimento é utilizado também no ensino da escrita, em particular nos estudos dos gêneros, e se exemplifica com clareza no estabelecimento da tipicidade do falado e do escrito. As perspectivas que reconhecem polos opostos para o falado e o escrito como recurso metodológico para estabelecer um contínuo sobreposto de gêneros (textuais) trabalham com a ideia de tipicidade do falado (o gênero tipicamente falado), por um lado, e do escrito (o gênero tipicamente escrito), por outro, situando-os nos polos extremos do contínuo. É, portanto, em função da ideia de gêneros típicos da fala - tipicidade que identifica, por exemplo, o gênero "conversa espontânea" com o modo de enunciação falado -, que se produz um objeto igual a si mesmo, o típico, a partir do qual se diferenciam todos os demais gêneros falados. Observe-se que o contato entre dois gêneros situados em pontos distantes no contínuo tenderia a zero ou, de fato, corresponderia a zero (caso dos prototípicos), o

${ }^{9}$ Craia (2005) afirma que o pensamento ocidental sempre primou pela submissão da diferença; reprimindo-a e condenando-a, sempre, a não ser primeira, a não ser princípio, a ser potência derivada. No contexto dessa reflexão, afirma que deixamos escapar algo quando subjugamos a diferença através do princípio da identidade, cuja fórmula básica é $\mathrm{A}=\mathrm{A}$. Essa fórmula define, segundo o autor, grande parte do pensamento filosófico e científico. Com a diferença concebida, numa primeira impressão, como o mal, busca-se "salvá-la" na representação: como identidade, como analogia, como oposição, como semelhança. 
que leva a concluir que, para a maioria dos gêneros, seriam possíveis apenas eventuais combinações entre gêneros vizinhos (não importa a combinação: gêneros falados com falados, escritos com escritos ou falados com escritos) ou entre gêneros cujas características de concepção e produção resultariam em uma terceira (e nova?) especificidade, a dos gêneros híbridos (cf. MARCUSCHI, 2001, p. 41).

Note-se que as três especificidades (o típico falado, o típico escrito e o híbrido) não preveem a heterogeneidade como propriedade constitutiva dos gêneros em geral, o que contradiz a condição de possibilidade básica para a emergência de qualquer gênero: a das relações intergenéricas. A combinação prevista para gêneros vizinhos é, por sua vez, igualmente não constitutiva. Condicionada à vizinhança entre gêneros, essa alteridade no sentido fraco é definida, na verdade, pelo critério situacional, responsável, sobretudo, pelo registro (formal ou informal), que, supostamente, determinaria - por proximidade de registro - a seleção das relações intergenéricas cabíveis à conformação final de um dado gênero. Trata-se, no caso dos gêneros escritos, de mais um exemplo contingencial de heterogeneidade na escrita.

Outro exemplo em que a alteridade é concebida em seu sentido fraco é o da relação fala/escrita tal como é vista pela tradição escolar. Nesse caso e no que se refere especificamente à escrita, pensar a alteridade em seu sentido fraco é pensar a fala presente na escrita como uma interferência. Reconhece-se a sua heterogeneidade, mas ela é vista como circunstancial, contornável e, até mesmo, indesejável. Trata-se, portanto, da heterogeneidade na escrita.

Quando propus, em 1997, a ideia da heterogeneidade da escrita, me baseei na formulação de Street (1984), que, por sua vez, a tomava de Clanchy, historiador segundo o qual a mudança "da memória para o registro escrito na Inglaterra medieval foi facilitada "pela continuada mistura ["mix"] dos modos oral e letrado" (CLANCHY apud STREET, 1984 , p. 10), mistura que teria levado as formas escritas a serem "adaptadas à prática oral" mais do que a imporem a ela uma mudança radical.

Associei, então, essa ideia do hibridismo entre formas orais e formas escritas de comunicação à produção escrita de pré-universitários. Propus 
que esse modo híbrido de constituição da escrita seria mais bem caracterizado pela ideia de heterogeneidade, de modo que trouxesse uma noção de alteridade em seu sentido forte. Trata-se, neste caso, da heterogeneidade da escrita.

Com essa denominação, procuro recorrer a uma concepção de alteridade que se distancie do estabelecimento de diferenças a partir de uma identidade que se autodefina isoladamente. Com isso, busco evitar o paradoxo que há em se admitir que existe comparabilidade entre modos de enunciação por meio de eventuais traços comuns e, ao mesmo tempo, se afirmar que os comparáveis são exteriores entre si. No caso particular da escrita, deixa-se de buscar a sua suposta pureza para se discutir os fenômenos que marcam a sua heterogeneidade constitutiva. Alguns deles são atualmente conhecidos, por exemplo, por meio da noção de multimodalidade ${ }^{10}$, esta também carente, por vezes, de uma explicitação sobre o papel da alteridade. $\mathrm{Na}$ visão que defendo, os fenômenos que remetem ao campo do falado não são vistos como "interferência" da fala na escrita, mas como constitutivos da produção escrita, isto é, concebida como um modo de enunciação, a escrita vai além de uma perspectiva meramente textualista para dar atenção ao sujeito e sua relação com a linguagem ${ }^{11}$. O específico das chamadas modalidades oral e escrita da linguagem torna-se, pois, o fato de serem, ambas, heterogêneas, isto é, comportarem em si a presença de práticas sociais de diferentes modos de expressão, o que permite dizer que, em cada uma delas, está presente a alteridade constitutiva (gestos, por ex., na fala; gesto e prosódia, por ex., plasmados na escrita). Gestos e prosódia aproximam-se, nesse sentido, do papel dado por Voloshinov/Bakhtin à entoação expressiva por meio da qual fica marcada uma experiência social do sujeito, que, na sequência, aproximarei da noção de representação.

\footnotetext{
${ }^{10}$ Cf., por exemplo: Kress, G. (2004).

${ }^{11}$ Sobre a relação do sujeito com a linguagem, conferir Abaurre, Fiad e Mayrink-Sabinson (1997).
} 


\subsubsection{Heterogeneidade e representação}

Tenho defendido que a heterogeneidade da escrita se organiza segundo três eixos mobilizados pelo sujeito no ato da escrita. Desse modo, as características do texto (escrito ou falado), ligadas às várias dimensões da linguagem, seriam consideradas como frutos da relação dialógica entre representações do escrevente sobre a fala e sobre a escrita, considerado, ainda, um terceiro eixo nesse diálogo, marcado pelas representações sobre a relação do dizer atual com o já-dito (com o já-falado/escrito). Mas em que consiste considerar essas representações do escrevente?

Basicamente, consiste em ter em conta o que o escrevente faz ao articular representações sociais sobre a fala e sobre a escrita. Atentar para as representações do sujeito é, pois, considerar, na elaboração do texto, a experiência social do escrevente, acima aludida.

Entendo por experiência social um conjunto de características incorporadas pelo sujeito com base no papel e na procedência sociais, no grau de escolaridade, no sexo, na idade, nas crenças, nas filiações ideológicas, no status socioeconômico relativo ao grupo de origem e a outros grupos sociais - todas elas determinações históricas do sujeito que, isoladamente ou em conjunto, permitem supor certas avaliações sobre os mais variados temas e que, como medidas - ainda que imprecisas - de balizamento, acabam por servir como parâmetro para a avaliação não apenas do dito, mas do próprio dizer sobre um dado tema. Em outras palavras, seu reconhecimento permite atribuir um acabamento absoluto (VOLOSHINOV/BAKHTIN, 1926 - s.d.) para o enunciado. Para desenvolver um pouco mais esta reflexão, parto de duas perguntas: (a) por que podemos dizer que há um acabamento absoluto do enunciado?; e (b) por que podemos dizer que o enunciado nunca apresenta um acabamento de sentido?.

Por um lado, pode-se dizer que existe um acabamento absoluto do enunciado. $\mathrm{O}$ exemplo fictício abaixo procura mostrar como a entoação (e os gestos) marcam uma experiência social no uso da linguagem: 
- Carlinhos, pega o balde pra mamãe?

(nenhuma resposta)

Segundos depois:

- Carlos, pega o balde pra mãe.

- 'Pera.

Segundos depois:

- Jo-sé-Car-los, pega o balde pra mãe!

- Anh?

- PEGA O BALDE!

Neste exemplo, as ênfases buscadas pela sugestão de diferentes entoações sinalizam por onde caminha a experiência social do sujeito que enuncia. Como é essa mãe? Onde ela mora? De que normalmente ela se ocupa?... A entoação (e os gestos), que dão acabamento absoluto ao enunciado e põem o interlocutor em situação de réplica, marcam uma determinada experiência social do falante, selando, já no ato de produção, o vínculo entre língua, sociedade e história. Dito de outro modo: da experiência social nascem a entoação e os gestos (e, quem sabe, em alguma medida, o estilo) que dão o chamado acabamento absoluto do enunciado concreto e do texto. Também a conformação do texto pode ser pensada em termos de entoações que se articulam e se hierarquizam. Desse modo, tanto quanto os enunciados, os textos podem ser captados pelo acabamento absoluto que é percebido pelo ouvinte/leitor. São ilustrativas disso as proposições de Chacon (1998) sobre o ritmo da escrita. No caso do texto escrito, a própria divisão em parágrafos pode resultar numa expressão sentida como a conta-gotas, por repetidas subdivisões, ou, quando elas faltam, suscitar a percepção de uma expressão em jorro. A cada um dos casos, por meio de associações particulares, o ouvinte/leitor atribui a quem escreve determinada experiência social. A entoação e os gestos põem enunciado e texto em ponto de serem replicados ao caracterizarem a experiência social de onde se produz a enunciação e, por meio de seu reconhecimento, o acabamento absoluto do enunciado.

Pode-se, pois, dizer - e isto é muito importante - que o acabamento absoluto do enunciado e do texto não coincide, necessariamente, com o final estrutural do enunciado ou do texto, podendo ser estabelecido sempre que a entoação e o gesto permitam antecipar - mais (ou menos) 
consistentemente - a experiência social do sujeito. No intercâmbio verbal falado, é principalmente esse reconhecimento que entra em jogo nas intervenções que interrompem a fala alheia antes que a parte verbal do enunciado esteja completamente realizada. Suposta ou realmente reconhecida a experiência social, o interlocutor se autoriza a intervir, lançando mão do que, em função dessa percepção, dá como presumido para o sentido. No intercâmbio verbal escrito, é, também, a conformação da prosódia e dos gestos plasmados na escrita que permitem ao leitor atribuir um lugar de onde avaliar a experiência social do escrevente. Replica-se, portanto, ao dito, isto é, a "o que" se diz, mas também e, talvez, sobretudo, ao dizer, isto é, ao sujeito reconhecido como representante de uma experiência social em função das práticas sociais que mobiliza para a composição do texto.

Por outro lado, o enunciado concreto se caracteriza também por um aspecto de inacabamento. Toda réplica - incluindo: aquelas relativas a enunciados verbalmente concluídos; aquelas feitas a enunciados não inteiramente verbalizados na comunicação oral ou escrita e aquelas feitas a enunciados não integralmente lidos -, se baseia no fato de que, ao acabamento absoluto do enunciado e à situação de resposta por ele produzida, opõe-se o não acabamento do seu sentido. Essa propriedade do enunciado de não ser acabado no tocante a seu sentido se dá em função da avaliação que quem escuta ou lê necessariamente faz do enunciado. Em síntese, para replicar, é preciso dar o enunciado como acabado, mas, do ponto de vista do sentido, o enunciado nunca é acabado no ato de sua produção. Seu sentido depende sempre das réplicas (das avaliações) que provoca e, por isso, mesmo quando a réplica se baseia no enunciado verbalmente completo, ainda assim não se pode falar de acabamento do sentido, pois isto limitaria a observação apenas ao ato de produção do enunciado. O acabamento de sentido está, pois, no outro, isto é, na réplica que se abre a nova resposta.

O sujeito é, portanto, levado a replicar pela ação do acabamento absoluto do enunciado, por meio do qual se dá o reconhecimento da experiência social do interlocutor. O dizer ou o modo de dizer, que permite identificar a procedência de falantes e escreventes responsáveis pelo dito, 
talvez seja o principal fator mobilizador de réplica. No entanto, toda réplica, uma vez produzida, também passa a se submeter ao acabamento absoluto do enunciado, a partir do qual o reconhecimento de uma nova experiência social - desta vez no respondente - está igualmente aberta ao não acabamento do sentido.

Para concluir a exposição deste quinto fundamento teórico para o ensino da escrita, cabe reter, finalizando, que o sentido forte de alteridade contribui para observar como se dá a integração de práticas sociais díspares na produção escrita. A alteridade é o disparador da heterogeneidade, correspondendo à exterioridade constitutiva de todo processo de escrita. Ela está presente na enunciação escrita ( $3^{\circ}$ fundamento teórico apresentado) e, portanto, nas atualizações singulares do diálogo nos gêneros $\left(1^{\circ}\right.$ fundamento) e atua: (a) opacificando o aparentemente autoexplicativo e supostamente transparente exercício da escrita escolar, no qual o efeito da alteridade se marca, apenas indiciariamente, no fio do discurso $\left(2^{\circ}\right.$ fundamento); e (b) opacificando a suposta produção puramente verbal e a própria condição de sujeito empírico, respectivamente, pela ação de presumidos sociais e pelas determinações histórico-discursivas que o sujeito empírico assume na qualidade de sujeito do discurso (4 ${ }^{\circ}$ fundamento).

\section{CONSIDERAÇÕES FINAIS}

Mesmo que se admita que a institucionalização de um conteúdo curricular lida necessariamente com a estabilidade do objeto de ensino proposto na qualidade de currículo formal, essa estabilidade com que joga a institucionalização dos objetos de ensino (os gêneros, no caso em questão) não se confunde com a abordagem a ser dada no trabalho efetivo com seu ensino e produção. A nomeação de um conteúdo não corresponde, em geral, à fixação de um conceito por parte dos documentos oficiais. No entanto, só a reflexão teórica e, sobretudo, o alcance relativo de seu poder de explicação sobre um dado conteúdo formalmente proposto pode movê-lo de seu lugar de institucionalização para a vida. 
Os fundamentos teóricos aqui propostos visam a abrir essa possibilidade para o futuro professor; mais a isso do que a lhe fornecer um instrumento imediatamente aplicável. A formulação de conceitos de trabalho para o ensino da escrita é muito mais produtiva quando confrontada com as situações concretas de sala de aula e, como adiantei no início, quando esses fundamentos teóricos permitem que os conceitos de trabalho sejam concebidos de tal modo que sejam permeáveis às diferentes situações da prática didática criadas pelos diferentes sujeitos nela envolvidos. Naturalmente, a maleabilidade dos conceitos de trabalho só é garantida quando o professor em formação toma as rédeas dos pressupostos teóricos que julga produtivo mobilizar.

Resumindo a discussão feita neste trabalho, as diferentes perspectivas aqui aproximadas resultam em fundamentos teóricos. Da perspectiva dialógica do Círculo de Bakhtin, resulta (I) o fundamento teórico que determina que o processo de escrita se desencadeia a partir do diálogo atualizado em cada gênero do discurso. Da perspectiva indiciária de Ginzburg, resulta (II) o fundamento teórico que determina que o processo de escrita se marca nas pistas deixadas no fio do discurso e que sua explicação não se limita ao estritamente linguístico, requerendo um trabalho com a opacidade do material linguístico e não com a sua suposta transparência. Da perspectiva pragmático-enunciativo, resulta (III) o fundamento teórico que determina que o processo de escrita só se deixa observar quando a escrita se realiza como um modo de enunciação, ou seja, quando não é reduzida ao código alfabético que, em outro sentido, ela também é. Da perspectiva discursiva, em parte derivada do círculo de Bakhtin e, em parte, da Análise do Discurso Francesa, resultam os dois últimos fundamentos teóricos aqui propostos e que determinam: (IV) que a captação do processo de escrita não se limita ao aspecto verbal, mas inclui, simultaneamente, o presumido social dos gêneros do discurso (concebido como a amplitude sociocultural e histórica do próprio aspecto verbal dos gêneros) e a relação problemática entre sujeito empírico e sujeito do discurso; e (V) que a apreensão do caráter plural da escrita inclui: a consideração da alteridade em seu sentido forte (o outro tomado como constitutivo do sujeito do discurso), a heterogeneidade constitutiva (não circunstancial) da escrita e a representação que se faz do outro nas réplicas (representação tanto do dizer quanto do dito). 
Com esses fundamentos pretende-se, portanto, que os conceitos de trabalho levados à sala de aula: deem um lugar para o sujeito (e para a alteridade) na escrita e chamem a atenção para a escrita como processo; forneçam modos de constatação da opacidade da linguagem naquilo que fica indiciado no fio do discurso; redirecionem a atenção para com a escrita, passando da modalidade para o modo de enunciação, este que se dá segundo gêneros do discurso; e, finalmente, observem a relação do dizer atual com o já-dito e com o por dizer.

\section{REFERÊNCIAS}

ABAURRE, M.B.M. Oral and written texts: beyond the descriptive illusion of similarities and differences. Campinas: Unicamp, 1989 [mimeo.]. . Lingüística e psicopedagogia. In: SCOZ, B. J. L. et al. (Orgs.) Psicopedagogia: o caráter interdisciplinar na formação e atuação profissional. 1reimpr. Porto Alegre: Artes Médicas, 1990. p. 186-216.

ABAURRE, M. B. M., FIAD, R. S., MAYRINK-SABINSON, M. L., GERALDI, J. W. Considerações sobre a utilização de um paradigma indiciário na análise de episódios de refacção textual. Trabalhos de Linguística Aplicada, v. 25, p. 5-23, Jan.-Jun. 1995.

ABAURRE, M. B. M.; FIAD, R. S.; MAYRINK-SABINSON, M. L. Cenas de aquisição da escrita. Campinas: Mercado de Letras/Associação de Leitura do Brasil (ABL), 1997.

ADAM, J-M. A linguística textual: introdução à análise textual dos discursos. São Paulo: Cortez, 2008.

BAKHTIN, M. Estética da criação verbal. São Paulo: Martins Fontes, 1992. CHACON, L. Ritmo da escrita: uma organização do heterogêneo da linguagem. São Paulo: Martins Fontes, 1998.

CINTRA, M.S.M. Hibridismo e plasticidade na constituição dos gêneros do discurso. Trabalhos de Linguística Aplicada, v. 48, n. 1, p. 23-39, Jan./Jun. 2009. CORRÊA, M.L.G. O modo heterogêneo de constituição da escrita. São Paulo: Martins Fontes, 2004.

. As perspectivas etnográfica e discursiva no ensino da escrita: o exemplo de textos de pré-universitários. Revista da ABRALIN, v. Especial, p. 333-356, 2011. 
CRAIA, E.C.P. Deleuze e a ontologia: o ser e a diferença, In: ORLANDI, L.B.L. (Org.). A diferença. São Paulo: Editora da Unicamp, 2005. p. 55-90.

DUCROT, O. Princípios de semântica linguística (dizer e não dizer). São Paulo: Cultrix, 1972.

FOUCAULT, M. A ordem do discurso. 3. ed. São Paulo: Loyola, 1996.

GERALDI, J. W. Linguagem e ensino: exercícios de militância e divulgação. Campinas: Mercado de Letras - ALB, 1996.

GINZBURG, C. Mitos, emblemas, sinais: morfologia e história. São Paulo: Companhia das Letras, 1989.

. O extermínio dos judeus e o princípio de realidade In: MALERBA, J. (Org.) A história escrita: teoria e história da historiografia. Trad. Henrique E. R. Lima Filho. São Paulo: Contexto, 2009. p. 211-232.

KRESS, G. Reading Images: Multimodality, Representation and New Media. (2004). Disponível em:

$<$ http://www.knowledgepresentation.org/BuildingTheFuture/Kress2/Kress2.html $>$. Acesso em: 15 set. 2009.

LEA, M. R.; STREET, B. V. The "Academic Literacies" model: theory and applications. Theory into practice, v. 45, n. 4, p. 368-377, 2006.

MARCHEZAN, R. C. Diálogo. In: BRAIT, B. (Org.) Bakhtin: outros conceitoschave. São Paulo: Contexto, 2008. p. 115-132.

MARCUSCHI, L. A. Da fala para a escrita: atividades de retextualização. São Paulo: Cortez, 2001.

. Gêneros textuais: definição e funcionalidade. In: DIONÍSIO, A. P.; MACHADO, A. R.; BEZERRA, M. A. (Org.). Gêneros textuais e ensino. Rio de Janeiro: Lucerna, 2003. p. 19-36.

MATTOS, M. A. B. Linguagem movente e sacramento. In: CORRÊA, M. L. G. \& BOCH, F. (Org.) Ensino de língua: representação e letramento. Campinas:

Mercado de Letras, 2006. p. 225-232.

PÊCHEUX, M. Semântica e discurso: uma crítica à afirmação do óbvio. 3. ed. Campinas: Editora da UNICAMP, 1997.

. O discurso: estrutura ou acontecimento. Campinas: Pontes, 1990.

POSSENTI, S. Notas sobre o sentido da expressão "sentido literal". Estudos Linguísticos, v. 28, p. 65-70, 1999.

SIGNORINI, I. Letramentos multi-hipermidiáticos: complexificação do objeto grafocêntrico. In: TEIXEIRA E SILVA, R. (et al.) (Eds.) 2012. III SIMELP: A formação de novas gerações de falantes de português no mundo. China, Macau: Universidade de Macau. CD-ROM. 
STREET, B.V. Literacy in theory and practice. Cambridge: Cambridge University Press, 1984.

. "Hidden" features of academic paper writing. Working Papers in Educational Linguistics, v. 24, n. 1, p. 01-17, 2009.

TFOUNI, L. V. O dado como indício e a contextualização do(a) pesquisador(a) nos estudos sobre compreensão da linguagem. D.E.L.T.A., v. 8, n. 2, p. 205-223, 1992.

VYGOTSKY, L. S. A formação social da mente. 2. ed. São Paulo: Martins Fontes, 1988.

VOLOSHINOV, V. N. / BAKHTIN, M. M. Discurso na vida e discurso na arte (sobre poética sociológica). Trad. para uso didático da versão inglesa de 1976: Carlos Alberto Faraco e Cristóvão Tezza, s.d.

Recebido em: 04/06/13. Aprovado em: 27/11/13.

Title: Theoretical bases for the teaching of writing Author: Manoel Luiz Gonçalves Corrêa Abstract: The objective of this study is to identify the underlying theoretical foundations for the development of practical working concepts (STREET, 2009) applicable to the teaching of writing, guided by the interrelationship between ethnographic and discursive traditions, with particular emphasis, however, on the discursive perspective. In sum, the study strives to establish parameters for the development of practical working concepts that do not disassociate linguistic reflection (based on the operation of language, the written word, and discourse) from the broader consideration of writing and the teaching of writing. The core objective of the teaching of writing is to enable the practical working concepts applied in the classroom to permeate the various experiences of didactic practice created by the diversity of subjects engaged in the process. This approach ensures that the process will be founded on explicit theoretical parameters to address key questions relating to writing and, at the same time, achieve greater distance from the more traditional practice of defining specific models for purposes of reproduction.

Keywords: Theoretical Principles. Teaching. Writing.

Título: Bases teóricas para la enseñanza de la escritura Autor: Manoel Luiz Gonçalves Corrêa

Resumen: Este trabajo establece parámetros teóricos para la elaboración de conceptos de trabajo para la enseñanza de la escritura (STREET, 2009), partiendo de la relación entre las 
perspectivas etnográfica y discursiva, pero fijándose en esta última. Se busca, en sintesis, establecer parámetros para la elaboración de conceptos de trabajo que no disocien reflexión lingüistica (fundada en el funcionamiento de la lengua, del texto y del discurso) y reflexión sobre la escritura y su enseñanza. La finalidad visada en la enseñanza de la escritura es hacer con que los conceptos de trabajo, aplicables en el aula, sean permeables a las diferentes situaciones de la práctica didáctica creadas por los diferentes sujetos en ella involucrados. La expectativa es que, así elaborados, a medida que se fundamenten en parámetros teóricos explícitos para el tratamiento de las cuestiones de escritura, se alejen de la práctica más común, que fija modelos para reproducción.

Palabras-clave: Fundamentos teóricos. Enseñanza. Escritura. 